\title{
RANCANGAN APLIKASI PENGADAAN ALAT PRAKTEK PENDIDIKAN DI PT DHERA PERKASA ABADI BERBASIS JAVA
}

\author{
Rahmah Oktaviani Rizki ${ }^{1}$, Wahyu Nur Cholifah ${ }^{2}$, Lies Sunarmintyastuti ${ }^{3}$ \\ Program Studi Informatika, Fakultas Teknik dan Ilmu Komputer, Universitas Indraprasta PGRI \\ Jalan Raya Tengah No 80, Kelurahan Gedong, Pasar Rebo, Jakarta Timur \\ rahmaoktaviani61@gmail.com ${ }^{1}$,wnurcholifah@gmail.com², liesbina@yahoo.com ${ }^{3}$
}

\begin{abstract}
Abstrak
PT. Dhera Perkasa Abadi merupakan perusahaan yang bergerak di bidang penyedia alat praktek pendidikan. Sistem yang berjalan memiliki kelemahan yaitu masih menggunakan Microsoft word dan Microsoft excel dalam penginputan data. Dan media penyimpanan data masih berupa arsip, yang besar kemungkinan akan rusak atau hilang. Tujuan dari penelitian pembuatan perancangan aplikasi pengadaan alat praktek pendidikan yang dapat mempermudah dalam mengelola data yang terdapat pada PT DHERA PERKASA ABADI dengan mengumpulkan data-data untuk menganalisis dan merancang sistem aplikasi pengadaan barang alat praktek pendidikan pada PT Dhera Perkasa Abadi. Dalam perancangan aplikasi ini dibuat dengan menggunakan PHP MyAdmin untuk database dan aplikasi NetBeans sebagai alat bantu pembuatan aplikasi sistem informasi tersebut. Aplikasi ini membantu proses pencatatan pendaftaran dan otomatisasi peminjaman, pengembalian, serta membantu mempercepat proses pembuatan laporan tersebut. Dengan adanya sistem aplikasi ini diharapkan dapat bermanfaat bagi PT Dhera Perkasa Abadi.
\end{abstract}

Kata Kunci: Java, MySQL, Aplikasi pengadaan barang

\begin{abstract}
PT. Dhera Perkasa Abadi is a company engaged in the provider of educational practice tools. The running system has a drawback that is still using Microsoft word and Microsoft excel in data input. And data storage media is still an archive, which is likely to be damaged or lost. The purpose of the research is the design of educational practice tools procurement application that can facilitate in managing the data contained in PT DHERA PERKASA ABADI by collecting data to analyze and design the application system of procurement of educational practice tools goods at PT Dhera Perkasa Abadi. In designing this application is created by using PHP MyAdmin for NetBeans databases and applications as a tool for creating such information system applications. This app helps with the registration process and automation of borrowing, returns, and helps speed up the process of creating the report. With the application system is expected to be useful for PT Dhera Perkasa Abadi.
\end{abstract}

Keyword: Java, MySQL, Application of educational equipment

\section{PENDAHULUAN}

Kemajuan teknologi adalah sesuatu yang tidak bisa dihindari di era moderenisasi saat ini, karena kemajuan teknologi akan berjalan sesuai dengan kemajuan ilmu pengetahuan. Setiap inovasi diciptakan untuk memberikan manfaat positif bagi kehidupan manusia serta memberikan banyak kemudahan dalam melakukan aktifitas. Perkembangan teknologi informasi berbasis komputer kian canggih dan beragam terutama dalam dunia kerja. Dalam dunia kerja, komputer menjadi salah satu media sarana kerja yang dapat membantu dalam meningkatkan produktifitas dan kualitas kerja (Jogiyanto, 2010).

PT. Dhera Perkasa Abadi adalah perusahaan yang bergerak dibidang penyedia alat pendidikan. Sistem yang berjalan di PT. Dhera Perkasa Abadi memiliki kelemahan yaitu masih mengandalkan Microsoft word dan Microsoft excel dalam penginputan data barang sehingga dibutuhkan waktu yang lama dalam pencarian data barang. Dan media penyimpanan data masih berupa arsip, yang besar kemungkinan rusak atau hilang.

Dengan adanya masalah tersebut, maka perlu adanya pembenahan terhadap sistem yang sedang berjalan dan pengembangannya harus sesuai dengan kebutuhan saat ini, khususnya agar bisa membantu dan dapat mempermudah dalam menyajikan informasi, maka topik yang diambil untuk penelitian ini adalah Aplikasi Pengadaan Alat Praktek Pendidikan di PT. Dhera Perkasa Abadi. 
Berdasarkan latar belakang masalah diatas, maka dari itu peneliti mencoba untuk mengidentifikasikan masalah, yaitu sistem pengelolaan data yang sedang berjalan saat ini hanya mengandalkan cara manual, yaitu menggunakan Microsoft Word dan Microsoft Excel, sering terjadinya kesalahan dalam pencatatan data dan penyimpanan data yang masih berupa arsip dan Masih lambannya dalam pencarian data barang.

Adapun tujuan dari perancangan aplikasi pengadaan alat praktek pendidikan di PT Dhera Perkasa Abadi adalah sebagai berikut untuk membangun sebuah sistem aplikasi yang memberikan kemudahan manajemen data bagi administrasi perusahaan, agar mudah menganalisa, merancang dan mengimplementasikan sistem pengadaan barang dan meningkatkan pelayanan bagi perusahaan. Manfaat yang diharapkan dari penelitian ini agar memberikan manfaat untuk peneliti yaitu menambah pengetahuan dan wawasan baik teori maupun praktek melalui perancangan aplikasi pengadaan alat praktek dan memberikan kemudahan kepada perusahaan untuk meningkatkan pelayanan kepada customer.

\section{PENELITIAN RELEVAN}

Penelitian oleh (Metry Amelia, 2015) dengan judul Sistem Pengolahan Data Barang Paisley Thing dengan Menggunakan Java. Penelitian ini bertujuan untuk melakukan penelitian terhadap aplikasi pengolahan data barang mencakup informasi barang, yang bertujuan untuk mempermudah dan mengelola data pelanggan dan data produk yang terdapat di Paisley Thing agar pekerjaan menjadi efektif dan efisien serta membantu dalam menyelesaikan permasalahan pekerjaan yang berkenaan dengan pengelolaan data barang. Dalam tugas ini menggunakan bahasa pemrograman Java serta database MySQL.

Penelitian oleh (Anggunsari, 2017) dengan judul Perancangan Sistem Informasi Pengadaan Sarana dan Prasarana Fakultas Teknik Universitas Pasundan Bandung. Penelitian ini bertujuan untuk menganalisa sistem informasi pengadaan sarana dan prasarana yang dirancang peneliti dapat diterapkan dan merupakan salah satu solusi yang tepat bagi fakultas teknik Universitas Pasundan Bandung. Dalam tugas ini peneliti menggunakan bahasa pemrograman Java serta database MySQL.

Hubungan penelitian yang dibahas oleh peneliti dengan penelitian terdahulu adalah di perusahaan para peneliti dalam proses penginputan data masih mengandalkan Microsoft word dan Microsoft excel. Perbedaan yang membedakan dari penelitian terdahulu dengan penelitian yang peneliti lakukan yaitu adanya sistem pembelian barang yang tidak ada di peneliti sebelumnya.

\section{METODE PENELITIAN}

Metode Grounded Research (Mardiani, 2013) adalah reaksi terhadap metode penelitian yang asasnya verifikasi teori. Dalam Grounded Research, data merupakan sumber teori, dan teori disebut Grounded karena teori tersebut berdasarkan data. Tujuan dari Grounded Research adalah untuk mengadakan generalisasi empiris, menetapkan konsep-konsep, membuktikan teori dan mengembangkan teori. Metode yang digunakan dalam Grounded Research adalah (Yourdon, 2010) studi-studi perbandingan bertujuan untuk menentukan seberapa jauh suatu gejala berlaku umum. Penelitian juga bertujuan untuk menspesifikasikan konsep, maksudnya dalam mempelajari suatu kasus atau gejala maka perlu untuk membandingkan gejala atau kasus tersebut dengan kasus atau gejala serupa. Perbandingan demikian akan menjelaskan unsur-unsur baru khas dari kasus yang sedang dipelajari.

Metode Penelitian yang digunakan peneliti adalah (Yahya, 2010) Metode Grounded Research yaitu suatu metode penelitian berdasarkan pada fakta dan analisis perbandingan dengan tujuan mengadakan generalisasi emperis, menetapkan konsep, membuktikan teori, mengembangkan teori, pengumpulan dan analisis data dalam waktu yang bersamaan. Dalam penelitian ini data merupakan sumber teori atau teori berdasarkan fakta.

Dalam penelitian ini metode yang digunakan dalam pengumpulan data yaitu dengan observasi bagaimana sistem yang berjalan saat ini di perusahaan tersebut. Selain observasi, teknik lain yang digunakan adalah dengan mewawancarai karyawan yang bekerja di PT. Dhera Perkasa Abadi dengan menanyakan apa kelemahan dari sistem yang berjalan dan apa harapan dari perancangan 
aplikasi baru yang akan digunakan nanti . Tempat penelitian dilakukan pada PT. Dhera Perkasa Abadi yang terletak di Jalan Taman Malaka Selatan Blok B3 No. 7 - 1 Pondok Kelapa - Jakarta Timur 13460

\section{HASIL DAN PEMBAHASAN}

Sistem baru yang diusulkan peneliti merupakan komputerisasi bagi sistem lama atau sistem berjalan, dimana cara kerja atau prosedur sistem yang baru tidak jauh berbeda. Perubahan dari sistem yang lama ke sistem yang baru diharapkan dapat membantu dan mengatasi masalah yang timbul pada sistem yang lama. Dengan semakin berkembangnya teknologi komputer dalam menangani berbagai masalah perlu ditinjau kembali manfaat apa yang dapat diperoleh dari penggunaan komputer. Karena dirasakan sangat perlu untuk diadakan sistem komputerisasi berbasis java, maka disini peneliti mencoba mengusulkan adanya sistem Pengadaan Alat Praktek Pendidikan berbasis java pada PT Dhera Perkasa Abadi. Dengan peralihan sistem yang lama ke sistem yang baru diharapkan dapat mengatasi masalah yang ada dan meningkatan kualitas kinerja karyawan.

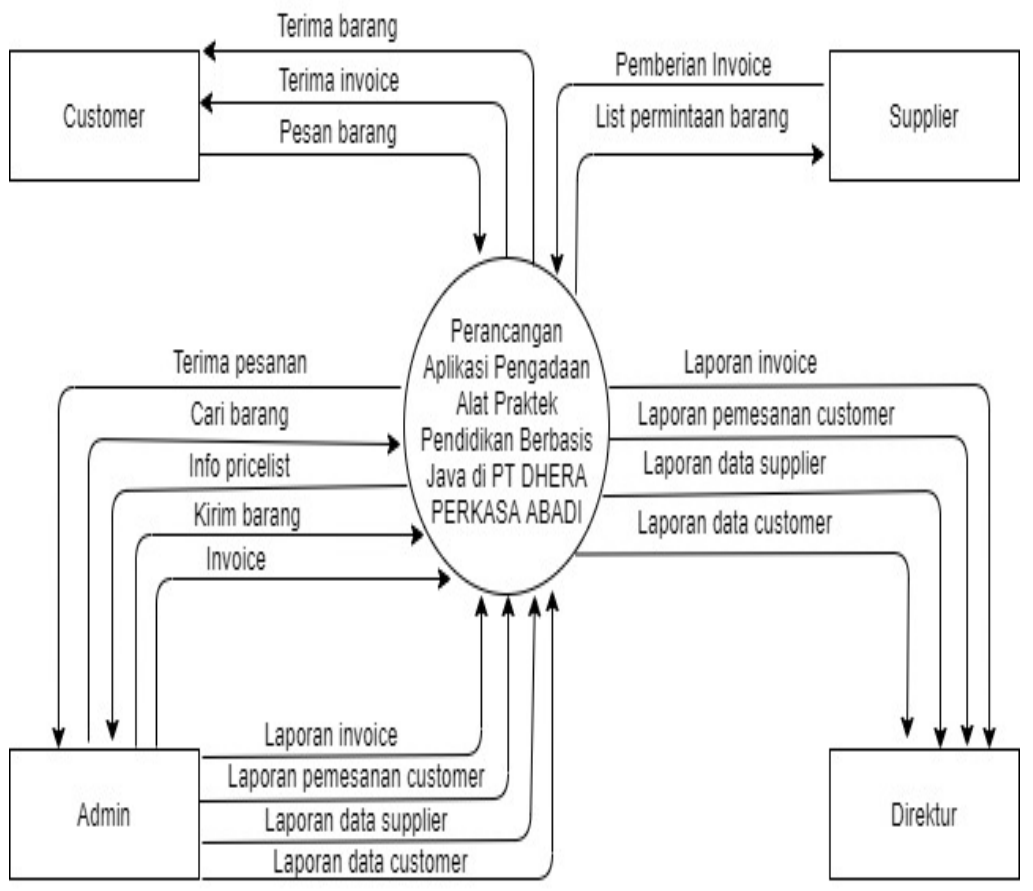

Gambar 1. Diagram Konteks

Diagram konteks yang diusulkan merupakan rancangan awal dari aplikasi yang akan dibuat yang berdasarkan pada sistem kerja yang berjalan di PT. Dhera Perkasa Abadi dengan pembaharuan yang disesuaikan dengan hasil yang telah ditentukan. 


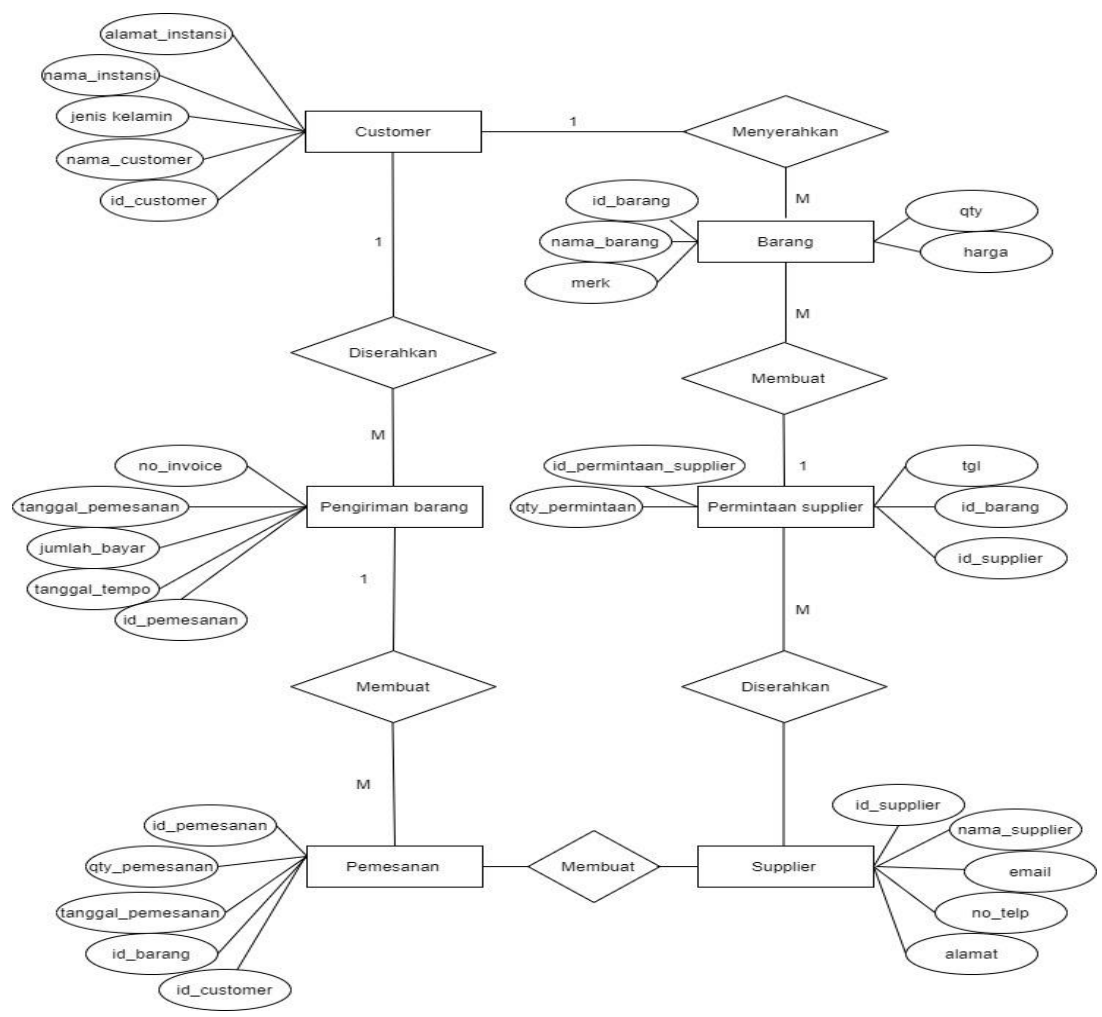

Gambar 2. Entity Relationship Diagram (ERD)

Diagram ERD menggambarkan hubungan antara entitas database dari rancangan aplikasi pengadaan barang.

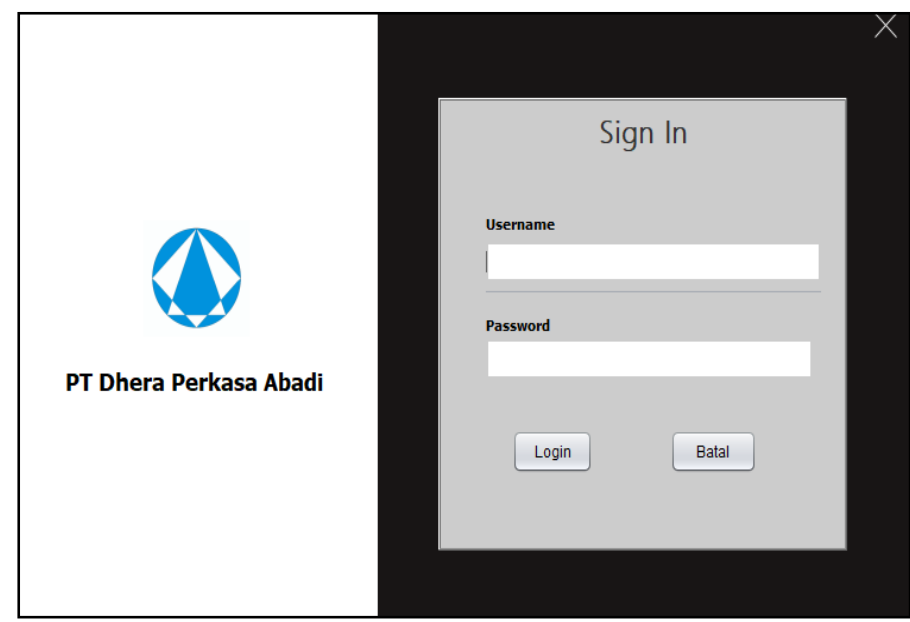

Gambar 3. Menu Login

Tampilan menu login ini muncul di awal saat pengoperasian aplikasi perpustakaan untuk diisi oleh admin sebagai user. 


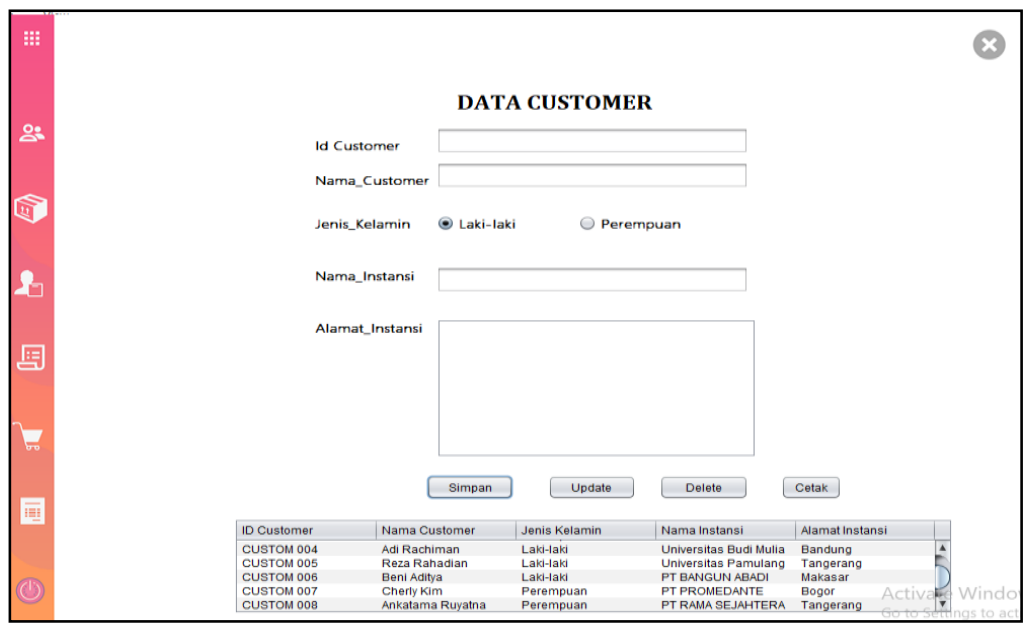

Gambar 4. Tampilan Form Data Customer

Tampilan form data customer ini berfungsi untuk memasukan atau menambah data customer kedalam basis data.

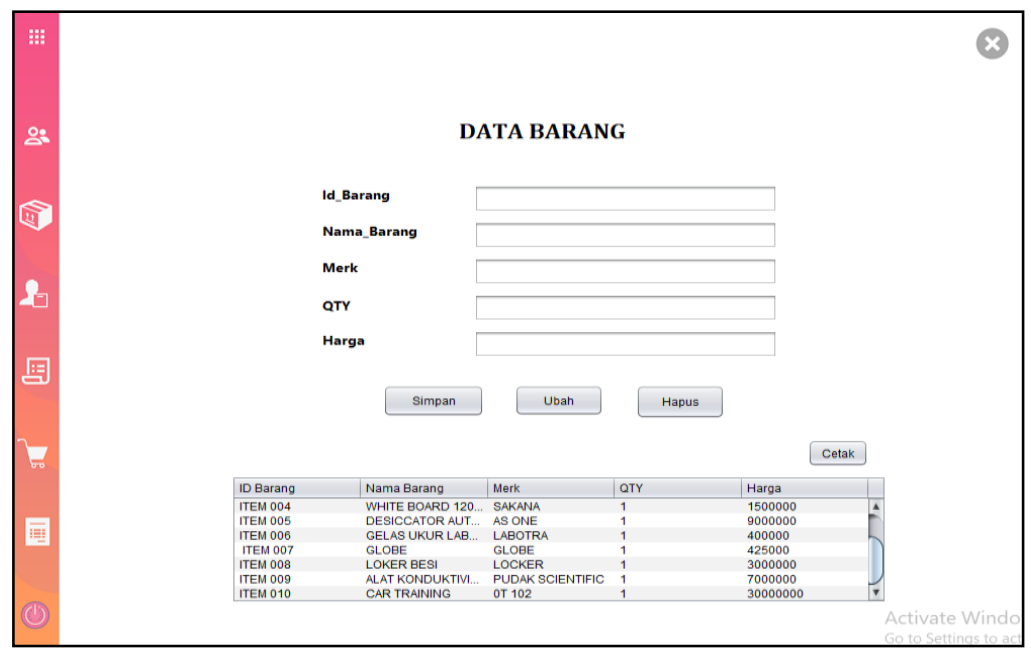

Gambar 5. Tampilan Form Data Barang

Tampilan form data barang ini berfungsi untuk memasukan atau menambah data barang kedalam basis data.

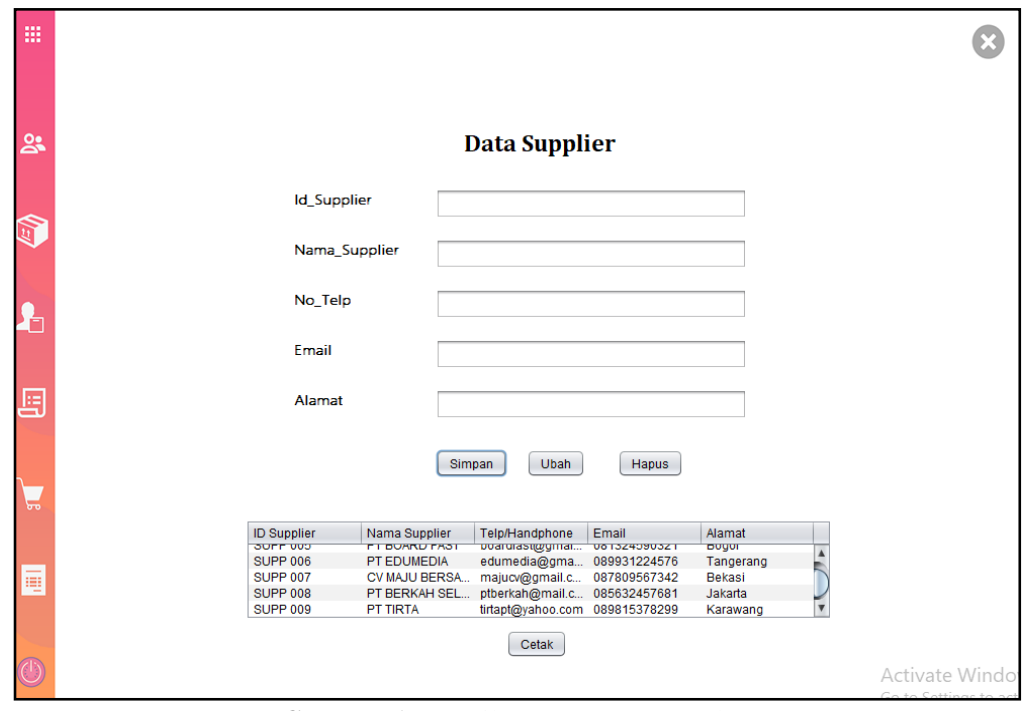

Gambar 6. Tampilan Form Data Supplier 
Tampilan form data supplier ini berfungsi untuk memasukan atau menambah data supplier kedalam basis data.

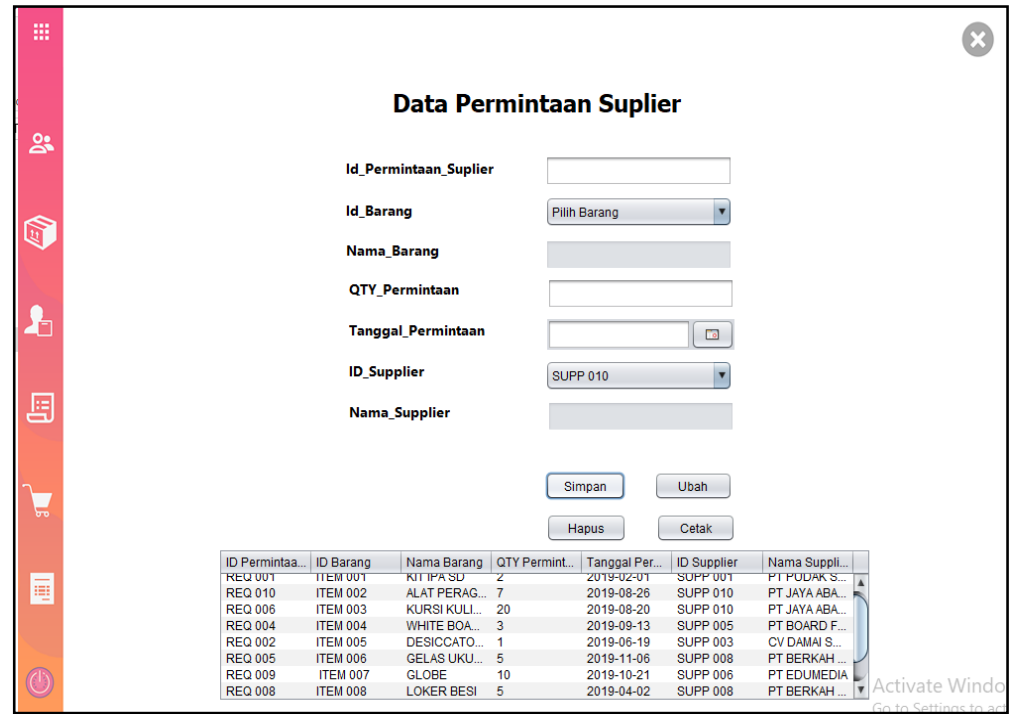

Gambar 7. Tampilan Form Data Permintaan Supplier

Tampilan form data permintaan supplier ini berfungsi untuk memasukan atau menambah data barang yang akan dipesan ke supplier kedalam basis data.

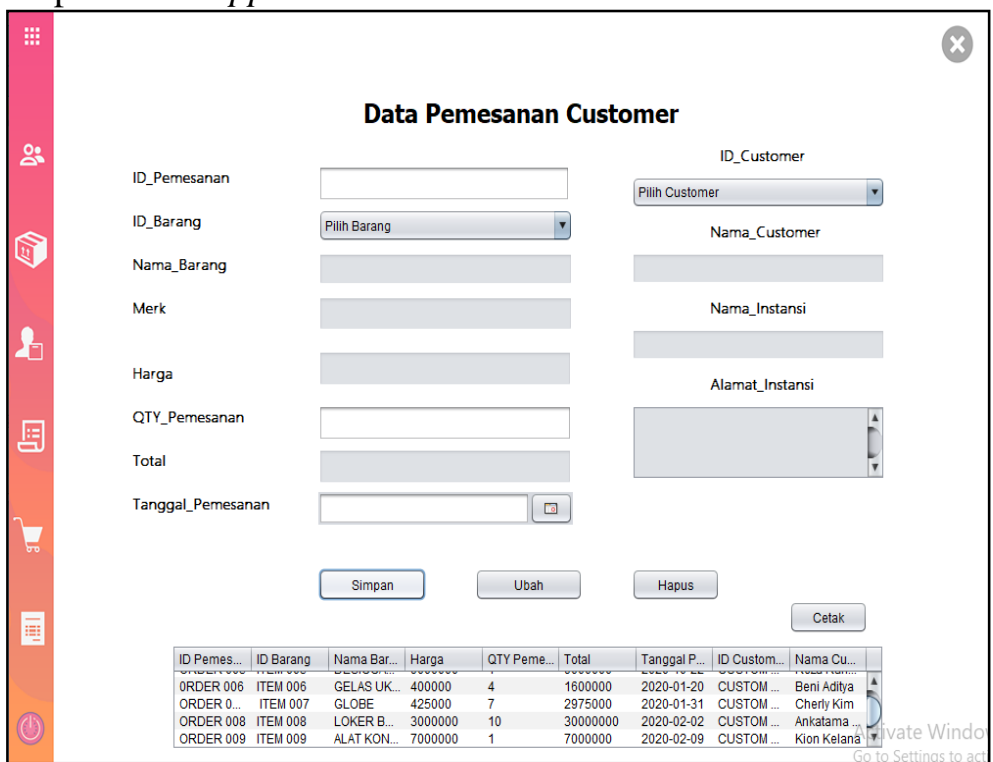

Gambar 8. Tampilan Form Data Pemesanan Customer

Tampilan form data pemesanan customer ini berfungsi untuk memasukan data barang pesanan customer kedalam basis data. 


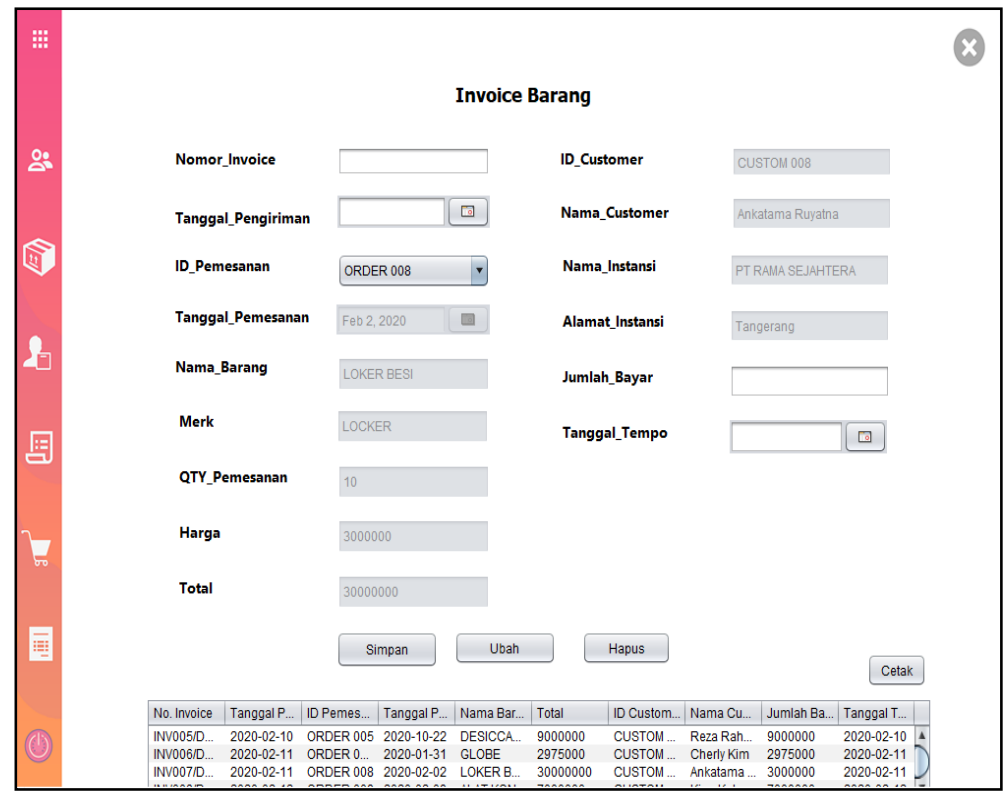

Gambar 9. Tampilan Form Invoice Barang

Tampilan form invoice barang ini berfungsi untuk membuat informasi tentang invoice pemesanan barang customer.

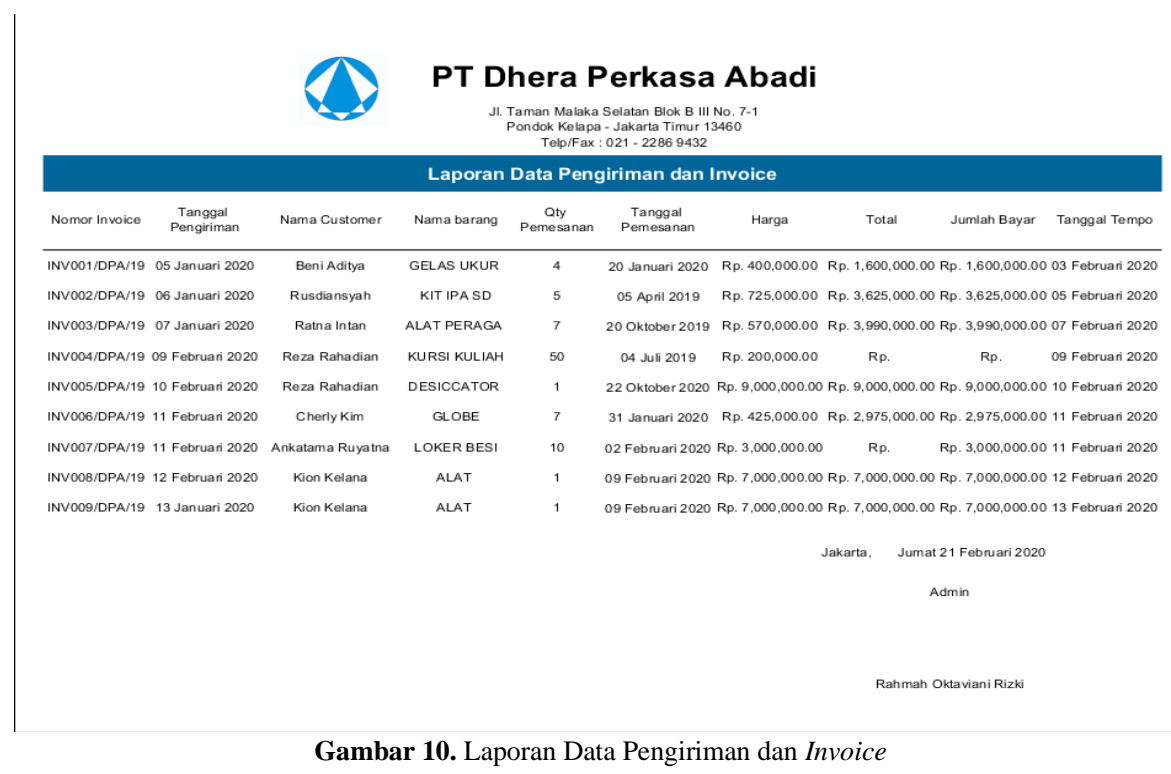

Tampilan keluaran laporan data pengiriman dan invoice berisikan informasi data pengiriman dan invoice yang akan diberikan kepada customer.

\section{SIMPULAN}

Berdasarkan penelitian dan analisis yang diuraikan di atas maka peneliti dapat menarik simpulan bahwa dengan adanya aplikasi pengadaan alat praktek memudahkan bagian administrasi dalam membuat laporan dengan waktu yang singkat dan efisien. Membangun sebuah sistem aplikasi yang memberikan kemudahan manajemen data bagi administrasi perusahaan. Agar mudah menganalisa, merancang dan mengimplementasikan sistem pengolahan data barang terhadap proses persediaan.

\section{DAFTAR PUSTAKA}

Anggunsari, D. (2017). Perancangan Sistem Informasi Pengadaan Sarana dan Prasarana Fakultas Teknik Universitas Pasundan Bandung. Universitas Pasundan Bandung. Jogiyanto. (2010). Analisis dan Desain Sistem Informasi. Graha Ilmu. 
Jurnal Riset dan Aplikasi Mahasiswa Informatika (JRAMI)

Vol 미 No 04 Tahun 2020

e-ISSN : $2715-8756$

Mardiani, Eri. (2013). Inventory Menggunakan Java Netbeans, XAMPP, dan IReport. Elex Media Komputindo.

Metry Amelia. (2015). Sistem Pengolahan Data Barang Paisley Thing dengan Menggunakan Java. Universitas Indraprasta PGRI.

Yourdon, E. (2010). Electronic Data Processing Structured Techniques System Analysis. Englewood Cliffs.

Yahya, Marzuqi. (2010). Panduan Pengadaan Barang/Jasa Pemerintah. Forum Sahabat. 